ORIGINAL ARTICLE

\title{
Healthcare Workers' Preparedness to tackle COVID-19: A Study on Knowledge and Compliance with Standard Precautions in a Tertiary Hospital in Southern Nigeria
}

\author{
Ogboghodo EO', Osaigbovo $\mathrm{II}^{2}$, Adio $F B^{1}$, Uwugiaren $E I^{3}$, Nwaogwugwu $C J^{1}$, \\ Obaseki DE ${ }^{4}$ Oko-oboh $G A^{1}$
}

${ }^{1}$ Department of Community Health, University of Benin Teaching Hospital, Benin City, Edo State. 2Department of Medical Microbiology, University of Benin Teaching Hospital, Benin City, Edo State. ${ }^{3}$ Department of Nursing Services, University of Benin Teaching Hospital, Benin City, Edo State.

${ }^{4}$ Office of the Chief Medical Director/Department of Anatomic Pathology, University of Benin Teaching Hospital, Benin City, Edo State.

Keywords

Compliance;

Knowledge;

Standard

Precautions,

COVID-19

\section{ABSTRACT}

Background: Hospitals may serve as amplifiers of infectious disease rates during outbreak situations. The strict implementation of and compliance with standard precautions (SPs) is the primary strategy for preventing healthcare-associated infections. This study was conducted to assess the knowledge and level of compliance with SPs in a tertiary hospital as a measure of preparedness to tackle the COVID-19 pandemic.

Methods: This descriptive cross-sectional study was conducted among healthcare workers selected using stratified sampling technique in the University of Benin Teaching Hospital, Benin City, Nigeria during the COVID-19 pandemic. Data was collected using an adapted, self-administered questionnaire and analyzed using IBM SPSS version 25.0. Knowledge and compliance with SPs were assessed using six domains each. Statistical measures for analysis were the odds ratios (OR) and 95\% confidence intervals (CI). The level of significance was set at $\mathrm{p}<0.05$.

Results: A total of 524 respondents with mean age $38.1 \pm 9.7$ years participated in this study. Majority, 432 (84.2\%) were female and $467(89.1 \%)$ were clinical staff. Overall, knowledge and compliance of SPs were good in $457(87.2 \%)$ and $293(60.0 \%)$ respondents, respectively. Clinical health workers were 2.5 (95\% CI: $1.3-5.1)$ times more likely to have good knowledge while respondents with poor knowledge were 0.5 (95\% CI: $0.3-0.9)$ times less likely to have good compliance with SPs.

Conclusion: Knowledge of SPs in the studied population was high and compliance was good. Continued education and behavioural change communication are needed to improve compliance especially in the face of a pandemic.

Keywords: Compliance; Knowledge; Standard Precautions, COVID-19

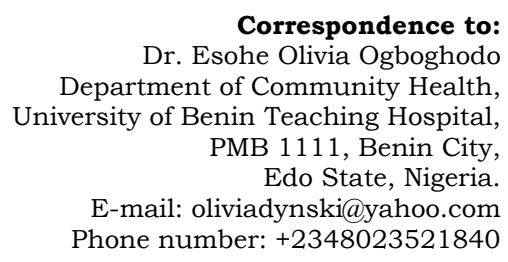

\section{INTRODUCTION}

Severe acute respiratory syndrome coronavirus 2 (SARS-CoV-2) which emerged in December 2019 in Wuhan, China, spread rapidly and subsequently escalated into a global pandemic by March, 2020.1 The 
highly contagious virus causes coronavirus disease 2019 (COVID-19) and is transmitted through respiratory droplets and close contact with infected persons. Transmission also occurs through airborne routes following aerosol-generating procedures and SARS-CoV-2 remains viable on surfaces for up to three days. ${ }^{2}$ The main clinical manifestations of COVID-19 are cough, fever and complications such as acute respiratory distress syndrome, pneumonia, and acute respiratory failure. ${ }^{3}$ However, both asymptomatic and pre-symptomatic individuals may also transmit the disease with high efficiency. ${ }^{3}$ The highly transmissible nature of SARS-CoV-2 was responsible for the unprecedented surge in case numbers witnessed worldwide, triggering a flurry of preparedness and response activities in healthcare facilities around the globe, each in anticipation of their fair share of patients.

In the public health response to infectious disease outbreaks, hospitals can be a double-edged sword, possessing the potential to strengthen or deter containment efforts according to their level of preparedness. ${ }^{4}$ This is because besides providing care for affected persons, hospitals can inadvertently become hotbeds of secondary disease transmission and risk thwarting public health containment efforts by amplifying the outbreak. ${ }^{5}$ The propensity for infectious diseases to spread within healthcare facilities must thus be addressed by hospital preparedness and response efforts if disease containment is to be attained. ${ }^{6}$ Past outbreaks of severe acute respiratory distress syndrome (SARS) in 2003, Ebola virus disease in 2014 and Middle east respiratory syndrome (MERS) in 2015 have repeatedly demonstrated the potential of healthcare facilities to serve as amplifiers of new or re-emerging communicable diseases. ${ }^{6,7}$ Likewise, during the earliest phases of the COVID-19 pandemic, some Chinese estimates put nosocomial COVID-19 transmission at rates as high as $41 \%$. These were attributed to failure to recognise the virus and institute appropriate standard precautions (SP).8-10 Later case series showed that in addition to isolation of positive patients, the use of face masks and intensified hand hygiene clearly prevented nosocomial transmission. ${ }^{11,12} \mathrm{~A}$ study conducted in a large United States (US) academic medical centre also suggested that rigorous infection control minimized the risk of hospital-acquired COVID-19. 10 These observational data emphasized infection prevention and control (IPC) as an invaluable facet of a hospital's preparedness and response strategy.

Preventing infectious disease transmission among healthcare workers (HCWs), patients and visitors is a critical component of safe healthcare delivery. ${ }^{13,14}$ Standard Precautions (SPs) including hand hygiene; use of personal protective equipment (e.g., gloves, masks, eyewear); respiratory hygiene /cough etiquette; sharps safety/safe injection practices; sterilization of instruments and devices; and cleaning /disinfection of environmental surfaces minimize the transfer of infectious 
microorganisms from patient to patient, patients to HCWs and from HCWs to patients. ${ }^{15}$ The implementation of SPs in normal routine circumstances will strengthen the HCWs capacity to put them into practice under stressful outbreak situations. ${ }^{4}$ During outbreak situations, the goals of IPC are to ensure the safety of all individuals present within the hospital, including patients, staff and visitors by reducing transmission of healthcareassociated infections; to enhance the hospital's ability to respond to an epidemic and to lower or eliminate the risk of hospitals becoming an avenue for epidemic amplification. ${ }^{4}$ Implementation of IPC within a facility is dependent on the sum total of individual HCW's knowledge and compliance with IPC practices as gaps in knowledge and practice among healthcare personnel constitute the fundamental driving force of outbreak amplification. ${ }^{5}$ Thus, a workforce that is knowledgeable about and compliant with SPs is a valuable asset in the hospital outbreak preparedness strategy for diseases with outbreak potential such as Lassa fever, Ebola virus disease and emerging coronaviruses including COVID19. 4

The overall level of knowledge concerning SPs among HCWs in Nigeria as reported from different studies is highly variable, ranging between $35-79 \% .{ }^{16-20}$ A study conducted in 2010 at the University of Benin Teaching Hospital (UBTH) assessing knowledge and practice of hand hygiene revealed that less than half of HCWs had good knowledge and practice. Therefore, this study was carried out to document the knowledge and level of compliance with standard precautions among HCWs as part of UBTH's preparation to tackle the COVID19 pandemic. Findings from the study provided information necessary for tailoring training and retraining needs of staff, planning behavioural change communication messages and overall strengthening of the hospital's response to the pandemic.

\section{METHODOLOGY}

This descriptive cross-sectional study was undertaken in April 2020 at the University of Benin Teaching Hospital (UBTH) Benin City, Edo State in southern Nigeria. The University of Benin Teaching Hospital is a 912 bedded facility that renders promotive, preventive, curative and rehabilitative services in various departments, including Internal medicine, surgery, Pediatrics, Mental health, Community health, Obstetrics and Gynecology, Radiology, Ear, Nose and Throat, Anesthesiology, Ophthalmology, Family Medicine and Dentistry. ${ }^{22}$ UBTH currently has a staff strength of over 4,000 employees. Prior to the COVID-19 pandemic, the Infection Prevention and Control Committee of the hospital had, in its bid to ensure safety, embarked on a hospital wide health education campaign on standard precautions. The hospital management had also upgraded its hand washing and waste management facilities and ensured that water which is a major determinant for sanitation especially in resource limited settings was made available at all times. At 
the start of the pandemic in Nigeria, the management of UBTH constituted a COVID19 response team. In addition to increasing the purchase and availability of facemasks, gloves and eye goggles (necessary for standard precautions and transmissionbased precautions), the local production of plastic aprons, coveralls and face shields was embarked upon. Also, signage and Information Education and Communication (IEC) posters on COVID-19 were placed at strategic locations, and advisories were regularly communicated to staff. The hospital also adopted the "No face mask, No entry" policy to ensure the mitigation of spread of COVID -19 by staff and visitors within the facility.

The study population comprised of all cadres of HCWs who have been in the facility's employment for at least six months prior to the survey in order to give an objective assessment on the knowledge of standard precautions, excluding those on annual or study leave at the time of the study. A HCW was defined as any member of staff in the health care facility involved in the provision of care for a COVID-19 patient, including those who have been present in the same area as the patient as well as those who may not have provided direct care to the patient but who have had contact with the patient's body fluids, potentially contaminated items or environmental surfaces. This included health care professionals, allied health workers and auxiliary health workers such as cleaning and laundry personnel, x-ray physicians and technicians, clerks, phlebotomists, respiratory therapists, nutritionists, social workers, physical therapists, laboratory personnel, cleaners, admission/reception clerks, patient transporters and catering staff. 23

A minimum sample size of 427 was calculated using the appropriate formulae for single proportion. ${ }^{24}$ This was calculated considering a standard normal deviate of 1.96 at a significance level of $5 \%$; p of $53.0 \%$ (representing the prevalence of PPE use among HCWs in a tertiary healthcare facility in Eastern Nigeria) 20 and a $10 \%$ attrition rate (non-response). Stratified sampling technique was employed in selecting health care workers for this study. The professional groups of the employees formed the basis of each stratum. Proportional allocation was used to determine the number of employees in each cadre. The sampling frame of each professional cadre was obtained from the administrative office. From each group, systematic sampling technique was used to select the respondents who met the inclusion criteria.

Five research assistants were trained for two days on data collection to enhance validity and repeatability of the research tools prior to survey. Data was collected using a selfadministered questionnaire containing open and closed ended questions adapted from a Centre for Disease Control document on Standard Precautions for all patient care. ${ }^{25}$ A detailed explanation on the survey was given to all eligible respondents and informed consent sought before the administration of the questionnaire. 
Returned questionnaires were checked for completeness by the research assistants.

Data was serialized and analysed using IBM SPSS version 25.0. Knowledge of standard precautions was assessed using 30 questions in 6 domains [moments of hand hygiene (8 questions), use of PPE (9 questions) and application of waste management (4 questions), cough etiquette (3 questions), safe injection practices (3 questions) and disinfection/sterilization (3 questions)]. A correct response was scored 1 and incorrect response scored 0 , giving a minimum score of 0 and a maximum score of 30. Scores were converted to percentage and scores $70 \%$ and above were adjudged as good knowledge of standard precautions, while scores less than $70 \%$ were adjudged as poor knowledge. The questions used for scoring knowledge were assessed for internal consistency and reliability using the Cronbach's alpha test, and a value of 0.742 was obtained.

Compliance with standard precautions was assessed with 19 questions in six domains viz hand hygiene, cough etiquette, waste management, PPE, safe injection practices and disinfection/sterilization, using a graded scale (always, sometimes, never). Scores of 3, 2 and 1 were given for any 'always', 'sometimes', and 'never' response, respectively. Scores were converted to percentages and a compliance level $60 \%$ and above was adjudged good while compliance level of less than $60 \%$ was adjudged poor. HCWs performing non-clinical roles were excluded from compliance assessment to prevent interpretation bias since majority of the items were not applicable to them. The questions used for scoring compliance were assessed for internal consistency and reliability using the Cronbach's alpha test, and a value of 0.835 was obtained.

Unadjusted and adjusted analyses using binary logistic regression were conducted using the 'enter approach' to determine significant predictors of the knowledge and compliance to standard precautions. The statistical measure for the analysis was the adjusted odds ratio and 95\% confidence interval. The level of significance was set at $\mathrm{p}<0.05$ for all statistical associations. Frequency tables and figures were used to present the results. Permission to conduct the study was also obtained from the hospital management. Informed consent was obtained from the respondents. Privacy and confidentiality were assured and respondents were informed of their right to decline participation or to withdraw from the study at any time they wished.

\section{RESULTS}

A total of 550 questionnaires were distributed, however, 524 questionnaires were retrieved giving a 95.3\% response rate. The mean age of respondents was $38.1 \pm 9.7$ years with $156(29.8 \%)$ seen in the 40-49 years age group. Respondents within the 60-69 years age group made up the least proportion of the study population at 2 $(0.4 \%)$. Four hundred and thirty-two respondents (82.4\%) were females, and 521 (99.4\%) practiced Christianity. A majority of 
respondents 488 (93.1\%) worked in the clinical departments, performing clinical roles in the hospital, and over half, 305 $(58.2 \%)$ had been in the employ of the hospital for less than ten years. (Table 1).

Table 1: Socio-demographic characteristics of respondents

\begin{tabular}{|c|c|c|}
\hline Variable & $\begin{array}{r}\text { Frequency } \\
(\mathrm{n}=524) \\
\end{array}$ & Percent \\
\hline \multicolumn{3}{|l|}{ Age group (years) } \\
\hline $20-29$ & 138 & 26.3 \\
\hline $30-39$ & 143 & 27.3 \\
\hline $40-49$ & 156 & 29.8 \\
\hline $50-59$ & 85 & 16.2 \\
\hline $60-69$ & 2 & 0.4 \\
\hline Mean \pm SD (years) & $38.1 \pm 9.7$ & \\
\hline \multicolumn{3}{|l|}{ Sex } \\
\hline Female & 432 & 82.4 \\
\hline Male & 92 & 17.6 \\
\hline \multicolumn{3}{|l|}{ Religion } \\
\hline Christianity & 521 & 99.4 \\
\hline Islam & 3 & 0.6 \\
\hline \multicolumn{3}{|l|}{ Occupation } \\
\hline Nurse & 368 & 70.2 \\
\hline Doctor & 60 & 11.5 \\
\hline Paramedic & 23 & 4.4 \\
\hline Admin staff & 22 & 4.2 \\
\hline Med. Lab Scientist & 15 & 2.9 \\
\hline Physiotherapist & 14 & 2.7 \\
\hline Pharmacist & 8 & 1.5 \\
\hline Others* & 14 & 2.7 \\
\hline \multicolumn{3}{|l|}{$\begin{array}{l}\text { Length of Service } \\
\text { (years) }\end{array}$} \\
\hline$<10$ & 305 & 58.2 \\
\hline $10-19$ & 157 & 30.0 \\
\hline $20-29$ & 52 & 9.9 \\
\hline$\geq 30$ & 10 & 1.9 \\
\hline
\end{tabular}

All, 524 (100.0\%) respondents had heard of standard precautions. Majority, 447 (85.3\%) indicated formal training as their source of information while 77 (14.7\%) got their information on standard precautions from social media, and $11(2.1 \%)$ respondents reported other outlets such as health facilities, books and seminars. Four hundred and eighty (91.6\%) of the respondents had received formal training on standard precautions within the last one year. Of these, 461 (96.0\%), 419 (87.3\%) and $413(86.0 \%)$ of respondents had received formal training on hand hygiene, disinfection/sterilisation and safe injection practices, respectively. Three hundred and fifty-one $(67.0 \%)$ of the respondents had received training in respiratory hygiene, making it the least acquired course among others provided. Majority $512(97.7 \%)$ of respondents were aware that the facility had an Infection Control Committee. (Table 2) Majority, 501 (95.6\%), of respondents had correct knowledge of the five moments of hand hygiene while 438 (83.6\%) knew the correct PPEs to wear during different activities that HCWs perform. Respondents showed least knowledge 203 (38.7\%) in disinfection and sterilization Overall, a higher proportion of respondents 457 $(87.2 \%)$ had good knowledge of standard precautions. (Table 2)

Table 3 shows the unadjusted and adjusted association between socio-demographic variables and knowledge of standard precautions. Upon adjustment, the category of healthcare worker was the only significant independent predictor of good knowledge of standard precautions.

HCWs performing clinical roles were 2.5 times more likely to have good knowledge compared to the HCWs performing non clinical roles. Although respondents who had served at most 10 years were also more likely to have good knowledge of standard precautions compared to those who had 


\begin{tabular}{|c|c|c|}
\hline Variable & Frequency & Percent \\
\hline \multicolumn{3}{|c|}{ Source of Information* $(n=524)$} \\
\hline Formal Training & 447 & 85.3 \\
\hline Social Media & 77 & 14.7 \\
\hline Colleagues & 49 & 9.4 \\
\hline Television & 47 & 9.0 \\
\hline Radio & 45 & 8.6 \\
\hline Friend & 38 & 7.3 \\
\hline Others** & 11 & 2.1 \\
\hline \multicolumn{3}{|c|}{$\begin{array}{l}\text { Received formal training in the last one year } \\
(n=524)\end{array}$} \\
\hline Yes & 480 & 91.6 \\
\hline No & 44 & 8.4 \\
\hline \multicolumn{3}{|c|}{ Training modules received $*(n=480)$} \\
\hline Hand Hygiene & 461 & 96.0 \\
\hline Disinfection/Sterilisation & 419 & 87.3 \\
\hline Safe Injection Practices & 413 & 86.0 \\
\hline Waste Segregation & 404 & 84.2 \\
\hline Use of PPEs & 398 & 82.9 \\
\hline Respiratory Hygiene & 351 & 73.1 \\
\hline \multicolumn{3}{|c|}{ Correct Knowledge of Standard Precautions* $(n=524)$} \\
\hline Hand hygiene & 501 & 95.6 \\
\hline PPEs & 438 & 83.6 \\
\hline Cough etiquette & 392 & 74.8 \\
\hline Safe injection practices & 386 & 73.7 \\
\hline Waste management & 320 & 61.1 \\
\hline Disinfection/Sterilization & 203 & 38.7 \\
\hline Overall Good Knowledge & 457 & 87.2 \\
\hline
\end{tabular}

*Multiple response questions **Others include: Hospital, Books, Personal studies, Seminars, etc.

spent more than 10 years, this was not statistically significant. Age and sex of the respondents did not significantly predict good knowledge of standard precautions.

Compliance was assessed among the HCWs performing clinical roles. Among the respondents, $347(71.2 \%)$ always performed hand hygiene, 269 (55.2\%) always had good compliance with cough etiquette and 235 (48.1\%) managed waste properly. Only 61 $(12.5 \%)$ respondents always complied with safe injection practices. (Table 4). Overall, $293(60.0 \%)$ of the respondents had a good compliance with standard precautions. Table 5 shows the unadjusted and adjusted association between socio-demographic variables, knowledge of standard precaution and compliance with standard precautions among HCWs performing clinical roles. Upon adjustment, age, sex and length of service of the respondents had no statistically significant association with compliance with standard precaution. However, the respondent's knowledge and compliance with standard precaution had statistically significant association. 
Table 3: Unadjusted and adjusted predictors of good knowledge of standard precautions

\begin{tabular}{|c|c|c|c|c|}
\hline Predictors & $\begin{array}{l}\text { Good } \\
\text { knowledge } \\
(n=457) \\
n(\%) \\
\end{array}$ & Unadjusted OR (95\% CI) & p-value & $\begin{array}{l}\text { Adjusted OR (95\% } \\
\text { CI) }\end{array}$ \\
\hline \multicolumn{5}{|c|}{ Age group (years) } \\
\hline$<40$ & $283(88.4)$ & $0.758(0.452-1.272)$ & 0.293 & $0.989(0.480-2.037)$ \\
\hline$\geq 40^{*}$ & $174(85.3)$ & 1 & & 1 \\
\hline \multicolumn{5}{|l|}{ Sex } \\
\hline Male & $82(89.1)$ & $0.802(0.393-1.637)$ & 0.544 & $1.314(0.620-2.784)$ \\
\hline Female* $^{*}$ & $375(86.8)$ & 1 & & 1 \\
\hline \multicolumn{5}{|l|}{ Category } \\
\hline Clinical & 413 (88.4) & $0.443(0.224-0.874)$ & 0.016 & $2.537(1.256-5.126)$ \\
\hline Non-clinical* & $44(77.2)$ & 1 & & 1 \\
\hline \multicolumn{5}{|c|}{$\begin{array}{l}\text { Length of Service } \\
\text { (years) }\end{array}$} \\
\hline$\leq 10$ & 304 (88.9) & $0.659(0.392-1.110)$ & 0.115 & $1.566(0.752-3.260)$ \\
\hline$>10^{*}$ & $153(84.1)$ & 1 & & 1 \\
\hline
\end{tabular}

The respondents with poor knowledge were 0.5 (95\% CI: $0.3-0.9)$ times less likely to have good compliance with standard precautions compared to those with good knowledge.

The major barriers to compliance with SPs identified were the lack of adequate facilities 222 (45.5\%), absence of regular training on infection control $183(37.5 \%)$ and the uncomfortable nature of PPEs 166 (34.0\%). Only 46 (9.4\%) of respondents perceived insufficient knowledge on SPs as a barrier to compliance (Table 6).

\section{DISCUSSION}

The implementation of standard precautions in normal routine circumstances strengthens the healthcare facility's capacity to put them into practice under stressful outbreak situations such as the COVID-19 pandemic.
This study assessed baseline knowledge and compliance with SPs among HCWs in UBTH as a measure of their preparedness to tackle the COVID-19 pandemic. Similar to an earlier study carried out in the same hospital where a majority of respondents $(55.2 \%)$ were in the $30-39$ years age bracket (mean age of $33.7 \pm 8.8$ years), majority of the respondents in the index study were aged between 20 - 49 years with a mean age of $38.1 \pm 9.7$ years. ${ }^{21}$ This is not surprising as said age group dominates the working population. It was also noted that a majority of the respondents were females and nurses.

This is similar to the findings of a study carried out in Enugu State, Nigeria. ${ }^{20} \mathrm{~A}$ majority of the respondents were Christians mirroring the fact that the southern states in Nigeria are predominantly Christian in contrast with the northern states which are predominantly Islamic. 
Table 4: Compliance with standard precautions among HCWs

\begin{tabular}{lrrr}
\hline Compliance Variable & $\begin{array}{r}\text { Always } \\
\mathbf{n}(\%)\end{array}$ & $\begin{array}{r}\text { Sometimes } \\
\mathbf{n}(\%)\end{array}$ & $\begin{array}{r}\text { Never } \\
\mathbf{n}(\%)\end{array}$ \\
\hline Hand Hygiene & $347(71.1)$ & $138(28.3)$ & $3(0.6)$ \\
Cough Etiquette & $269(55.1)$ & $199(40.8)$ & $20(4.1)$ \\
Waste Management & $235(48.2)$ & $247(50.6)$ & $6(1.2)$ \\
PPEs & & & $12(2.5)$ \\
Face mask & & $159(32.6)$ & $106(21.7)$ \\
Boots & $317(65.0)$ & $117(24.0)$ & $13(2.6)$ \\
Latex gloves & $265(54.3)$ & $278(57.0)$ & $82(16.8)$ \\
Coverall & $197(40.4)$ & $240(49.2)$ & $74(15.2)$ \\
Goggles & $166(34.0)$ & $252(51.6)$ & $113(23.1)$ \\
Face shield & $162(33.2)$ & $237(48.6)$ & $114(23.4)$ \\
Plastic aprons & $138(28.3)$ & $243(49.8)$ & $37(7.6)$ \\
Safe injection practices & $131(26.8)$ & $390(79.9)$ & $27(5.5)$ \\
Disinfection/Sterilisation & $61(12.5)$ & $80(16.4)$ & \\
Overall Compliance & $381(78.1)$ & & \\
Good & & & \\
\hline Poor & & &
\end{tabular}

Table 5: Unadjusted and adjusted predictors of compliance with standard precautions

\begin{tabular}{|c|c|c|c|c|}
\hline $\begin{array}{l}\text { Predictors of Compliance } \\
\text { with standard precaution }\end{array}$ & $\begin{array}{l}\text { Good } \\
\text { Compliance } \\
(\mathrm{n}=293) \\
\mathrm{n}(\%)\end{array}$ & $\begin{array}{l}\text { Unadjusted OR } \\
(95 \% \mathrm{CI})\end{array}$ & p-value & $\begin{array}{l}\text { Adjusted OR (95\% } \\
\text { CI) }\end{array}$ \\
\hline \multicolumn{5}{|l|}{ Age Group (Years) } \\
\hline$<40$ & $176(59.1)$ & $\begin{array}{l}1.120(0.781- \\
1.604)\end{array}$ & 0.538 & $\begin{array}{l}1.139(0.689- \\
1.883)\end{array}$ \\
\hline$\geq 40^{*}$ & $117(61.8)$ & 1 & & 1 \\
\hline \multicolumn{5}{|l|}{ Sex } \\
\hline Male & $50(58.1)$ & $\begin{array}{l}1.074(0.680- \\
1.697)\end{array}$ & 0.760 & $\begin{array}{l}1.044(0.647- \\
1.684)\end{array}$ \\
\hline Female* & $243(60.4)$ & 1 & & 1 \\
\hline \multicolumn{5}{|l|}{ Length of Service (Years) } \\
\hline$\leq 10$ & $185(57.9)$ & $\begin{array}{l}1.309(0.903- \\
1.898)\end{array}$ & 0.155 & $\begin{array}{l}0.722(0.428- \\
1.218)\end{array}$ \\
\hline$>10^{*}$ & $108(64.3)$ & 1 & & 1 \\
\hline \multicolumn{5}{|l|}{$\begin{array}{l}\text { Knowledge of Standard } \\
\text { Precautions }\end{array}$} \\
\hline Poor & $33(53.2)$ & $\begin{array}{l}0.512(0.289- \\
0.906)\end{array}$ & 0.020 & $\begin{array}{l}0.503(0.282- \\
0.898)\end{array}$ \\
\hline Good* & $260(61.0)$ & 1 & & 1 \\
\hline
\end{tabular}

${ }^{*}$ Reference category, $R^{2}=17.4 \%-23.1 \%$ 
Table 6: Challenges of compliance with standard precautions for COVID-19

\begin{tabular}{lrr}
\hline Variable & $\begin{array}{r}\text { Frequency } \\
\text { (n=488) }\end{array}$ & Percent \\
\hline Lack of adequate facilities for the practice of SP & 222 & 45.5 \\
Absence of regular training on infection control & 183 & 37.5 \\
PPEs are uncomfortable & 166 & 34.0 \\
Excess workload & 148 & 30.3 \\
Patients feel stigmatized when PPEs are used & 114 & 23.4 \\
Lack of a functional infection control committee & 111 & 22.7 \\
Time constraints & 108 & 22.1 \\
I believe I will not acquire infection in the hospital & 65 & 13.3 \\
Insufficient knowledge on SP & 46 & 9.4 \\
\hline
\end{tabular}

All respondents in this study were aware of standard precautions. This is in keeping with a study done in a tertiary healthcare institution in Enugu State where $94.4 \%$ of respondents were aware of standard precautions. ${ }^{20}$ The high level of awareness may be explained by the continuous and numerous awareness campaigns organized by the IPC Committee of the institution. The committee regularly organized awareness campaigns within the institution to guard HCWs from Lassa fever as Edo State is an endemic region for the viral disease. ${ }^{26}$ This also explains why majority of the respondents were aware of the IPC Committee. The high level of awareness is commendable as an increased awareness often translates to good knowledge of the precautions as seen in this study. In contrast, a study carried out amongst intensive care nurses in Egypt revealed that approximately two thirds (63.6\%) of the studied sample had unsatisfactory knowledge levels. ${ }^{27}$

The index study also showed that more respondents had received formal training in hand hygiene and disinfection/sterilization while use of PPEs and respiratory hygiene had the least number of respondents being trained in them in the preceding 12 months. This pattern is reflected in the levels of knowledge the respondents displayed in the study. A possible explanation for the pattern of training received by staff may be the nature of awareness campaigns run by the IPC committee prior to the advent of COVID19, which were targeted at HCW protection against Lassa fever, where respiratory droplets are not as significant in the transmission as with the novel coronavirus. This is gravely significant as respiratory hygiene is a particularly important intervention in disrupting transmission of COVID-19. Also, a lack of proper training on the use of PPEs may lead to improper handling of respiratory hygiene equipment such as nose masks by HCWs, putting them at a greater risk of infection with the virus.

The study revealed that respondents with fewer years of service were less likely to be knowledgeable of the SPs compared to those who had worked for longer than 10 years in the institution. Similarly, in a study conducted in Borno State, majority of respondents who had greater than 10 years of work experience had better knowledge. ${ }^{28}$ Experience comes with the years of services rendered, likewise the number of 
opportunities for training increases with time. Having younger workers with less knowledge of SPs puts them at risk of acquiring infections in the line of duty. Greater efforts should, therefore, be geared towards integrating more training on SP and infection prevention into the orientation program of new employees. Majority of the respondents always practiced good hand hygiene. This is an improvement from the study carried out in the same institution in 2010 , in which only $48.2 \%$ of the respondents were reported to practice good hand hygiene. ${ }^{21}$ The improvement may be explained by the recently upgraded hand hygiene facilities in strategic areas of the hospital, as well as the provision of hand sanitizers to all staff in the preceding 6 months. This is commendable as regular washing of hands interrupts the transmission of COVID-19 to a great extent, reducing the risk of infection for both HCWs and patients alike.

Less than half of respondents practiced proper waste management at all times and few respondents observed safe injection practices always. This is in consonance with a study carried out in two tertiary hospitals in Nigeria where a third of respondents usually recapped needles with both hands. ${ }^{29}$ Improper waste management is a cause for concern as this puts HCWs, especially those responsible for waste disposal, at risk of infection from contaminated waste. This is compounded by the ability of SARS-CoV-2 to survive for days on certain materials. The increased use of medical face masks within hospital premises during the COVID-19 pandemic has caused an increase in potentially infectious waste which if not properly managed and disposed of could put others at risk of infection with SARS-CoV-2.

Two-thirds of the study population always made use of face masks, about half always made use of boots and four in ten respondents made regular use of latex gloves. These findings are similar to findings of a study carried out in another tertiary hospital in Edo State. ${ }^{30}$ The differences in compliance with use of different PPEs may be linked to the availability of such equipment to the HCWs. Availability is thus one of the major determinants of PPE use. Overall, six in ten respondents were found to have good compliance with SPs. This is higher than findings of a 2012 study in two tertiary hospitals. ${ }^{30}$ The high levels of compliance may be associated with heightened awareness during the ongoing pandemic, as well as provision of necessary equipment. A high level of compliance with SPs connotes a safer environment in the hospital for HCWs and patients alike, as simple adherence to basic precautions have proven helpful in disrupting the transmission of hospital-acquired infections, including COVID-19. This study also found a statistically significant relationship between knowledge and compliance, where respondents with poor knowledge were more likely to have poor compliance with SPs. Similarly, a study carried out in another tertiary hospital in Edo State revealed a significant association between good knowledge of SP and good 
practice. ${ }^{30} \mathrm{HCWs}$ with proper knowledge have a better understanding of the consequences of wrong actions and therefore act accordingly to protect themselves and others. This in turn makes the hospital a safer environment for fellow workers and patients, helping curb the spread of diseases such as COVID-19. However, percentage compliance levels in this study may have been overestimated due to self-reporting.

In conclusion, this study revealed high levels of knowledge on SPs among the HCWs as well as a commendable compliance rate to these precautions likely attributable to extensive training opportunities provided in the immediate pre-pandemic period. However, the less than average waste management practices need to be addressed through behaviour change communication. Knowledge was found to be a significant predictor of compliance. Training on SPs should be comprehensive to arm HCWs with the tools to combat pathogens in diverse categories whether blood-borne or spread through respiratory means. This will ensure that HCWs imbibe the culture of SPs in normal times, providing them with the weapons to combat infectious disease in periods of crises such as pandemics.

Acknowledgement: The authors wish to acknowledge the health care workers who participated in the study.

Funding: This study was self-funded
Competing Interests: The authors declare

no competing interest

\section{Authors' contributions:}

EOO - Conception, design, statistical analysis, manuscript drafting for intellectual content, final approval of the version to be published.

IIO - Conception, design, manuscript drafting for intellectual content, final approval of the version to be published.

AF - Conception, design, statistical analysis, manuscript drafting for intellectual content, final approval of the version to be published.

EIU - Conception, design, statistical analysis, manuscript drafting for intellectual content, final approval of the version to be published.

JCN - Conception, design, statistical analysis, manuscript drafting for intellectual content, final approval of the version to be published.

DEO - Conception, design, manuscript drafting for intellectual content, final approval of the version to be published.

GAO - Statistical analysis, manuscript drafting for intellectual content, final approval of the version to be published.

\section{REFERENCES}

1. Sharma A, Tiwari S, Deb MK, Marty JL. Severe acute respiratory syndrome coronavirus 2 (SARS-CoV-2): a global pandemic and treatment strategies. Int $\mathrm{J}$ Antimicrob Agents 2020; 56(2): 106054. doi: 10.1016/j.ijantimicag.2020.106054

2. Van Doremalen N, Bushmaker T, Morris DH, Holbrook MG, Gamble A, Williamson BN. Aerosol and surface stability of SARS-CoV-2 as compared with SARSCoV-1. N Engl J Med. 2020; 382: 15641567. doi: 10.1056/NEJMc2004973.

3. Huang C, Wang Y, Li X, Ren L, Zhao J, $\mathrm{Hu} \mathrm{Y}$ et al. Clinical features of patients 
infected with 2019 novel coronavirus in Wuhan, China. Lancet 2020; 395: 497506. doi: 10.1016/S01406736(20)30183-5.

4. World Health Organisation. Hospital preparedness for epidemics. 2014. [Accessed on December 6, 2020] Available at

https://www.who.int/publications/i/ite $\mathrm{m} /$ hospital-preparedness-for-epidemics.

5. Chiarello LA, Tapper ML. Healthcare settings as amplifiers of infectious diseases. Emerg Infect Dis 2004; 10(11): 2048-2049.

10.3201/eid1011.040797_01.

6. Popescu S. Hospital bio-preparedness in the looming presence of SARS-CoV2/COVID-19. Health Sci Rep 2020; 3(2): e149. doi: 10.1002/hsr2.149

7. Selvaraj SA, Lee KE, Harrell M, Ivanov I, Allegranzi B. Infection rates and risk factors for infection among health workers during Ebola and Marburg virus outbreaks: a systematic review. J Infect Dis 2018; 218(S5): S679-S689. doi: $10.1093 /$ infdis/jiy435.

8. Zhou Q, Gao Y, Wang X, Liu R, Du P, Wang $\mathrm{X}$ et al. COVID-19 Evidence and Recommendations Working Group. Nosocomial infections among patients with COVID-19, SARS and MERS: a rapid review and meta-analysis. Ann Transl Med 2020; 8(10): 629. doi: $\underline{10.21037 / \mathrm{atm}-20-3324}$

9. Wang $\mathrm{D}, \mathrm{Hu} \mathrm{B}, \mathrm{Hu} \mathrm{C}$, Zhu F, Liu $\mathrm{X}$, Zhang J. Clinical characteristics of 138 hospitalisd patients with 2019 novel coronavirus-infected pneumonia in Wuhan, China. JAMA 2020; 323:10611069. doi: 10.1001/jama.2020.1585.

10. Rhee C, Baker M, Vaidya V, Tucker R, Resnick A, Morris CA, Klompas M. Incidence of nosocomial COVID-19 in patients hospitalized at a large US academic medical centre. JAMA Netw Open 2020; 3(9): e2020498. doi: 10.1001/jamanetworkopen.2020.20498

11. Cheng VCC, Wong SC, Chen JHK, Yip CCY, Chuang VWM, Tsang OTY et al. Escalating infection control response to the rapidly evolving epidemiology of the coronavirus disease 2019 (COVID-19) due to SARS-CoV-2 in Hong Kong. Infect Control Hosp Epidemiol 2020; 41(5): 493-498. doi: 10.1017 /ice.2020.58
12. Zhang G, Pan H, Hu X, He S, Chen Y, Wei $\mathrm{C}$ et al. The role of isolation rooms, facemasks and intensified hand hygiene in the prevention of nosocomial COVID19 transmission in a pulmonary clinical setting. Infect Dis Poverty 2020; 9(1): 104. doi: $10.1186 / \mathrm{s} 40249-020-00725-z$.

13. Aguwa EN. A Review of Sir Thomas Legge's Aphorisms and workplace personal protective equipment - Is there gap in knowledge, attitude and utilization? Occupational Medicine \& Health Affairs. 2013; 1(6): 134 doi: 10.4172/2329-6879.1000134

14. World Health Organization. Regional Office for the Western Pacific. Practical guidelines for infection control in health care facilities. Manila: WHO Regional Office for the Western Pacific. 2004. [Accessed 18 May, 2020]. Available at https://apps.who.int/iris/handle/ 1066 5/206946.

15. Centre for Disease Control. 2020. Standard Precautions. [Accessed 18 May, 2020.] Available on: https://www.cdc.gov/oralhealth/infecti oncontrol/summary-infectionprevention-practices/standardprecautions.html.

16. Ibeziako SN, Ibekwe RC. Knowledge and practice of universal precaution in a tertiary health facility. Niger $\mathrm{J}$ Med. 2006; 15(3): 250-254. doi: 10.4314/njm.v15i3.37223.

17. Isara AR, Ofili AN. Knowledge and practice of standard precautions among health care workers in the Federal Medical Centre, Asaba, Delta State, Nigeria. Niger Postgrad Med J 2010; 17(3): 204-209.

18. Otovwe A, Adidatimi PO. Knowledge, Attitude and Practice of standard precaution among health care workers in Federal Medical Centre Yenagoa, Nigeria. IOSR Journal of Pharmacy and Biological Sciences. 2017 12(4):79-86. doi: $10.9790 / 3008-1204037986$

19. Okechukwu EF, Motshedisi C. Knowledge and practice of standard precautions in public health facilities in Abuja, Nigeria. Int J Infect Control. 2012; 8(3). doi: 10.3396/ijic.v8i3.022.12

20. Arinze-Onyia SU, Ndu AC, Aguwa EN, Modebe I, Nwamoh UN. Knowledge and 
practice of standard precautions by healthcare workers in a tertiary health institution in Enugu, Nigeria. Niger $\mathrm{J}$ Clin Pract. 2018; 21(2): 149-155. doi: $10.4103 /$ njcp.njcp_69_17.

21. Omuemu VO, Ogboghodo EO, Opene RA, Oriarewo P, Onibere OT. Hand hygiene practices among doctors in a tertiary health facility in southern Nigeria. J Med Trop 2013;15(2):96-101. doi: $10.4103 / 2276-7096.123579$

22. University of Benin Teaching Hospital. About UBTH. UBTH. 2020. Available at: https://ubth.org/general-information/

23. World Health Organisation. Assessment of risk factors for coronavirus disease 2019 (COVID-19) in health workers: protocol for a case-control study. Available

at https://www.who.int/publications/i/ite $\mathrm{m} /$ assessment-of-risk-factors-forcoronavirus-disease-2019-(covid-19)-inhealth-workers-protocol-for-a-casecontrol-study

24. Jaykaran C, Tamoghna B. How to calculate sample size for different study designs in medical research. Indian $\mathrm{J}$ Psychol Med. 2013; 10(41):121-126. doi: 10.4103/0253-7176.116232.

25. Centre for Disease Control and Prevention. Standard Precautions for all patient care. 2016. [Accessed 18 May, 2020]

Available at:

https://www.cdc.gov/infectioncontrol/b asics/standard-precautions.html.

26. Centre for Disease Control and Prevention. Lassa Fever. Fact sheet. 2011. [Accessed 18 May, 2020]. Available at:

https://www.cdc.gov/vhf/lassa/pdf/fac tsheet.pdf

27. Eskander HG, Youssef W, Morsy M, Ali $\mathrm{H}$, Elfeky A. Intensive care nurses' knowledge and practices regarding infection control standard precautions at a selected Egyptian Cancer Hospital. Journal of Education and Practice 2013; 4(19): 160-174.

28. Abdulraheem IS, Amodu MO, Saka MJ, Bolarinwa OA, Uthman MMB. Knowledge, awareness and compliance with standard precautions among health workers in north eastearn Nigeria. J
Community Med Health Edu 2012; 2(3): 10-14. doi:10.4172/jcmhe. 1000131

29. Ogoina D, Pondei K, Adetunji B, Chima $\mathrm{G}$, Isichei $\mathrm{C}$, Gidado $\mathrm{S}$. Knowledge, attitude and practice of standard precautions of infection control by hospital workers in two tertiary hospitals in Nigeria. J Infect Prev 2015; 16(1): 1622. doi: $10.1177 / 1757177414558957$

30. Tobin EA, Asogun DA, Odia I, Ehidiamen G. Knowledge and practice of infection control among health workers in a tertiary hospital in Edo state. Direct Res J Health Pharm. 2013; 1(2): 20-27. 